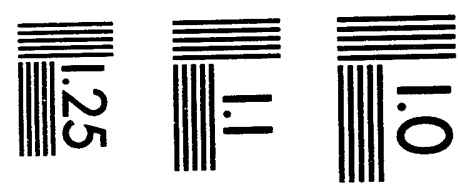

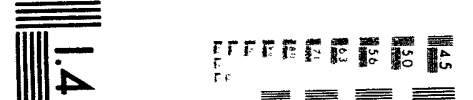

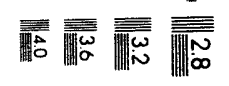

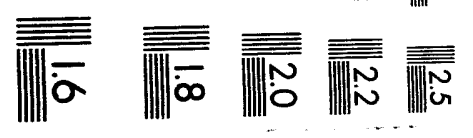



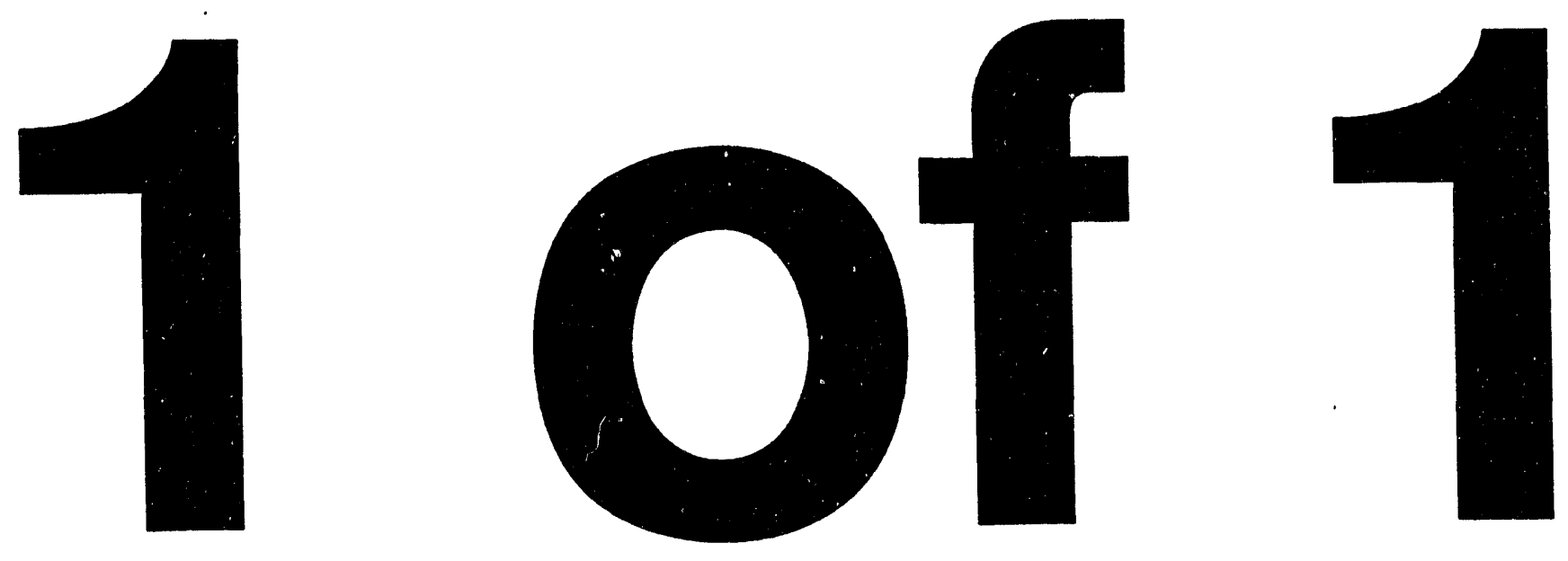


\title{
CNGBOCHS: An Integrated Ingres-Email-Interleaf System for Processing Change Requests Associated with GEMBOCHS, EQ3/6, and other Research Groups
}

\author{
Stephanie A. Daveler \\ Suzanne R. Lundeen \\ James $\mathbf{W}$. Johnson
}

Publication Date: June 1993

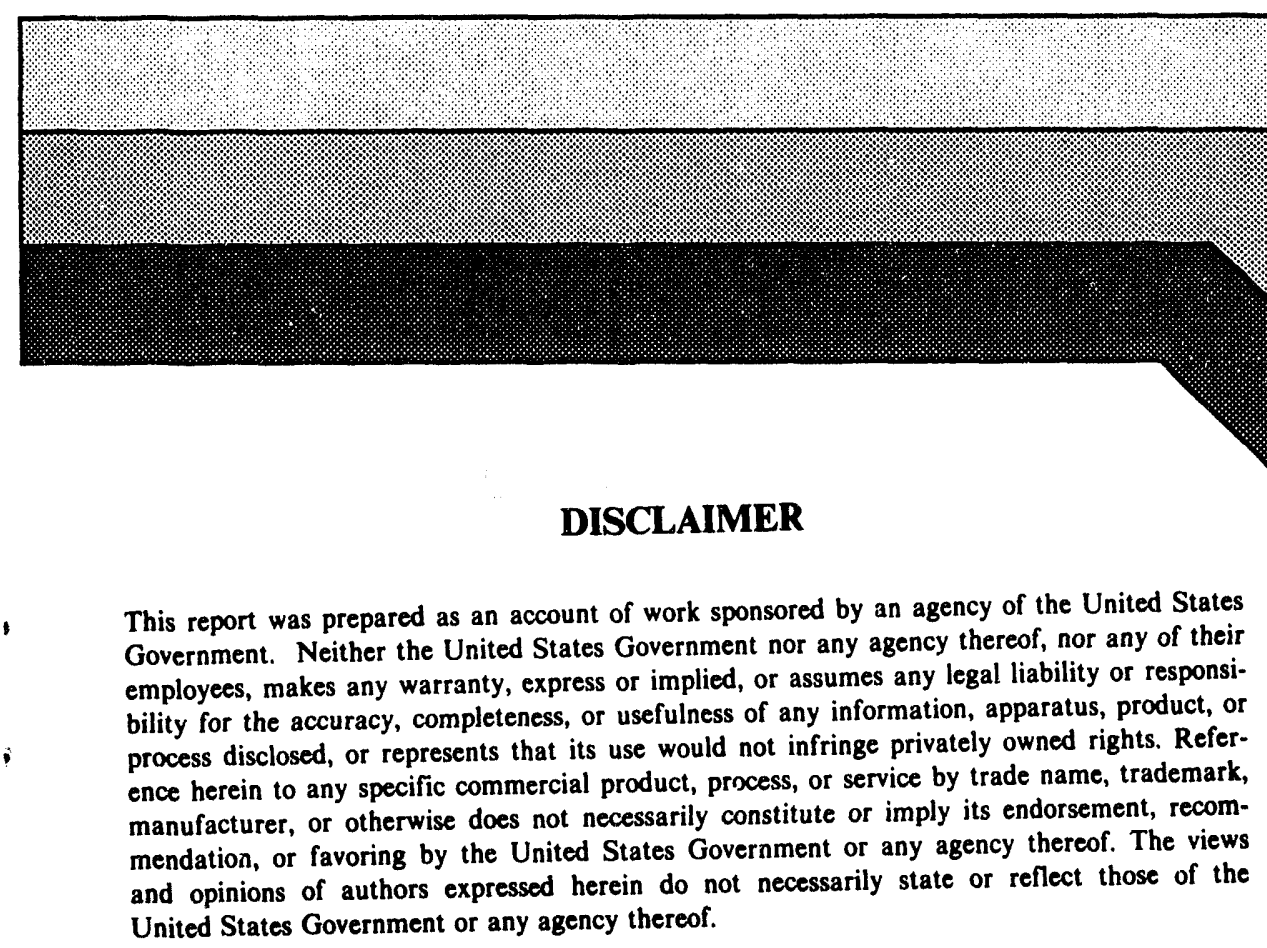

This report was prepared as an account of work sponsored by an agency of the United States Government. Neither the United States Government nor any agency thereof, nor any of their employees, makes any warranty, express or implied, or assumes any legal liability or responsibility for the accuracy, completeness, or usefulness of any information, apparatus, product, or process disclosed, or represents that its use would not infringe privately owned rights. Reference herein to any specific commercial product, process, or service by trade name, trademark, manufacturer, or otherwise does not necessarily constitute or imply its endorsement, recommendation, or favoring by the United States Government or any agency thereof. The views and opinions of authors expressed herein do not 
This document was prepared as an account of work sponsored by an agency of the United States Government. Neither the United States Government nor the University of California nor any of their employees, makes any warranty, express or implied, or assumes any legal liability or responsibility for the accuracy, completeness, or usefulness of any information, apparatus, product, or process disclosed, or represents that its use would not infringe privately owned rights. Reference herein to any specific commercial products, process, or service by trade name, trademark, manufacturer, or otherwise, does not necessarily constitute or imply its endorsement, recommendation, or favoring by the United States Government or the University of California. The views and opinions of authors expressed herein do not necessarily state or reflect those of the United States Government or the University of California, and shall not be used for advertising or product endorsement purposes.

Prepared by Yucca Mouniain Site Characterization Project (YMP) participants as part of the Civilian Radioactive Waste Management Program. The YMP is managed by the Yucca Mountain Site Characterization Project Office of the U.S. Department of Energy, Las Vegas, Nevada. 


\section{Table of Contents}

1.0 Introduction 1

2.0 The Email-CNGREQ Interface 2

2.1 Initiating a Change Request Using Email 2

2.2 Evolution of a Change Request Through the CNGBOCHS System 3

2.2 .1 "Review" Status 4

2.2.2 "Assigned" Status 5

2.2.3 "Verification" Status 5

2.2.4 "Completion" Status 6

3.0 The CNGBOCHS-CNGREQ Interface 6

3.1 CNGBOCHS Access Requirements 6

3.2 CNGBOCHS Start-up Procedure 6

3.3 CNGBOCHS Run-time Options 8

3.3.1 QUERY (R4): Interactive Specification of CNGREQ Queries 9

3.3.2 GO (R3): Directing Queries to CNGREQ 9

3.3.3 LIST: Writing Selected Change Requests to an ASCII File 10

3.3.4 SAVE (R5): Saving Modified or New Requests to CNGREQ 11

3.3.5 WRITE (R6): Printing Selected Change Requests 11

3.3.6 NEW (R5): Entering a New Change Request 12

3.3.7 CLEAR (R4): Clearing the Displayed Change Request Form 12

3.3.8 HELP (R2): Getting On-line Help 13

3.3.9 QUTT (R1): Exiting CNGBOCHS 13

3.4 Use of CNGBOCHS by Local Research Groups 14

$\begin{array}{lll}3.4 .1 & \text { Task Leaders } & 14\end{array}$

3.4.2 Technical Reviewers 15

$\begin{array}{ll}3.4 .3 \text { Programmers } & 16\end{array}$

$\begin{array}{lll}3.4 .4 \text { Verifiers } & 16\end{array}$

4.0 Concluding Remarks 17

APPENDIX A: CNGBOCHS Change-Request Form 18

APPENDIX B: CNGBOCHS Interleaf Document $\quad 20$ 


\section{Introduction}

Over the years, users of the GEMBOCHS thermodynamic database (GEMBOCHS is an acronym for Geologic and Engineering Materials: Bibliography Of CHemical Species) and the $E Q 3 / 6$ software package have periodically forwarded suggestions for improvement to the GEMBOCHS and EQ3/6 research groups. These correspondences typically report database or software errors that have been discovered during application, solicit the inclusion of additiona! or improved thermodynamic data, or suggest incorporation of new or alternate algorithms for performing various geochemical calculations. Traditionally, these suggestions have been made in person, over the phone, or via surface mail, and their resolution has often required additional correspondence. Hence, it has been difficult to maintain a complete, readily-accessible database of such transactions.

This difficulty has been eliminated by development of the CNGBOCHS software package (CNGBOCHS is an acronym for ChaNGe Bibliography Of CHemical Species). This system permits $G E M B O C H S$ and $E Q 3 / 6$ users to submit suggestions for improvement using the standard electronic mail system (hereinafter referred to as email); facilitates timely review, status notification, and resolution of these suggestions; and greatly simplifies the task of maintaining a comprehensive change-request database that can be relationally searched and selectively printed in rapid fashion.

The CNGBOCHS system consists of a dedicated Ingres database, CNGREQ (an acronym for ChaNGe REQuest database), which stores the change requests, review comments, and other information regarding their resolution history; an interactive Ingres application, CNGBOCHS, which provides a form-driven interface between local staff and this database, facilitates printing of the requests as Interleaf documents, and automatically disperses email notification to relevant parties when requests arrive and eac.: time their status is upgraded (from "review" to "assigned" to "verification" to "completion"); and the background CKMAIL utility (CKMAIL is an acronym for ChecK eMAIL), which monitors incoming email messages and files those addressed to CNGBOCHS in the CNGREQ database. CNGBOCHS currently supports the GEMBOCHS and $E Q 3 / 6$ research groups; additional groups can be readily included. The CNGBOCHS system is maintained together with the GEMBOCHS database and software library on a dedicated sun SPARCstation2 (node s60 of the local sun network), and utilizes Ingres version 6.4 .

The purpose of this document is to describe the procedure for submitting email change requests to $C N G R E Q$ and to present a succinct summary of the CNGBOCHS-CNGREQ interface: its local access, operation, and run-time options. 


\subsection{The Email-CNGREQ Interface}

The email-CNGREQ interface facilitates use of the standard email system to submit change requests and carry out all subsequent exchange of information between change requesters and those responsible for reviewing and resolving these requests. In this section we describe the procedure for submitting change requests via email, the evolution of such requests through the CNGBOCHS system, and the sequence of emait correspondence that tracks this evolution from "review" to "assigned" to "verification" to "completion" status.

\subsection{Initiating a Change Request Using Email}

Anyone having an email account and access to the "gov" domain can forward a change request in the form of a standard email message to any research group supported by CNGBOCHS (at present, the GEMBOCHS and EQ3/6 groups). The text format of such a message is completely unrestricted; however, the message must be addressed correctly, contain specific keywords in the subject field, and include certain critical information in the text field. Specifically, the message must be addressed to cngbochs@s60.es.llnl.gov, its subject field must be group request, where group must be one of the designated group identifiers (currently, gembochs or eq3/6), and its text must contain the sender's full name, preferred email address (only if different than the return address of the current message), and phone number, the version number of the relevant database and/or software, and a complete description of the request. (Note: If hardcopy attachments (e.g., journal articles) are to accompany the request, this should be noted in the request description, and the hardcopies forwarded to the appropriate party. The presence of these attachments will be noted in $C N G R E Q$, and they will be appended to the filed hardcopy of the change request itself.)

An example illustrating the use of email on a unix system to forward a change request to the GEMBOCHS group is given below. In this and all subsequent examples, em represents the standard email utility, <cr> denotes a carriage return, and all boldface entries are (system) or must be (user) specified exactly as shown.

\section{EXAMPLE}

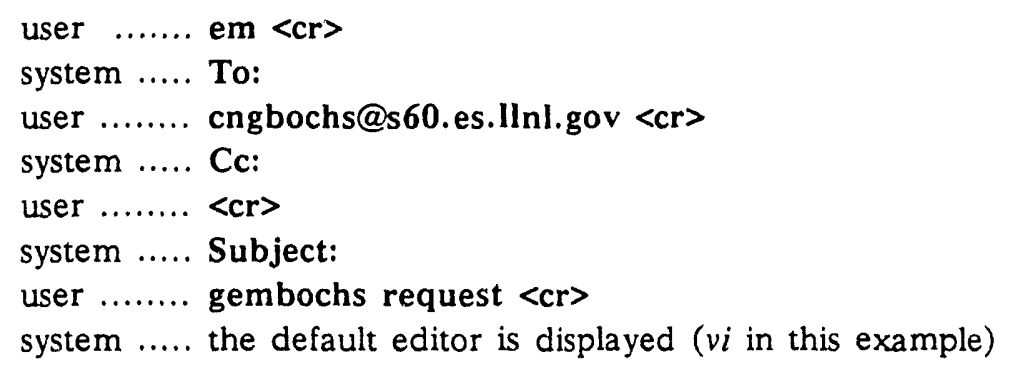


user enters text that describes the request; the following information must be supplied:

*** your full name and phone number

** your email address (only if different than the return address of this message)

** a complete description of the request

** the version of the database or software you are using (if applicable) exits the editor

system .... abort, display, help, include, justify, message, modify, receipt, save, send, userinfo, whoto:

user $\ldots . . .$. send $<\mathrm{cr}\rangle$

system .....e em $>$

user $\ldots . . .$. quit $<c r>$

\subsection{Evolution of a Change Request Through the CNGBOCHS System}

When a new change request arrives in the cngbochs mailbox, it is filed in the C'VGREQ database, assigned an $C R$ id number, its status is set to "review", and the appropriate task leader is notified of its arrival; this is all done automatically. The complete evoiution of any given request through the CNGBOCHS system is schematically illustrated in figure 1.

Figure 1.

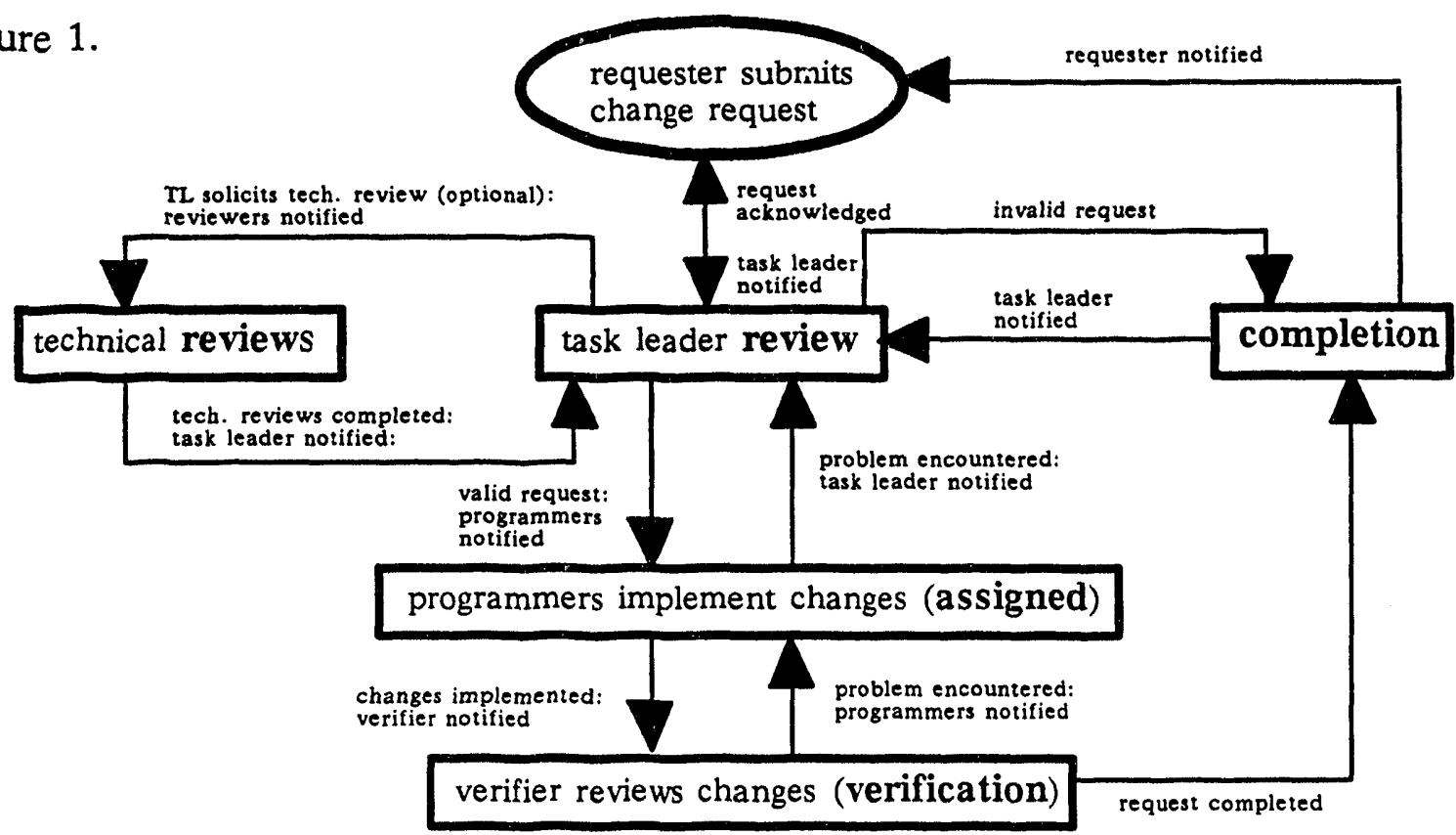

In this figure, the boldface entries specify current status of the request and the arrows indicate a change of status or review solicitation, both of which trigger automatic email notification of the relevant parties. The status categories are defined as follows. 


\subsection{1 "Review" Status}

As noted above, each incoming change request is initially assigned "review" status, and the appropriate task leader is notified. During this initial stage, the task leader reviews the request and has the option of soliciting additional technical reviews. If this option is selected, the task leader uses CNGBOCHS (see 3.4.1 for procedural details) to enter some initial comments regarding the request and assign additional reviewers from a current list of those available. The assigned reviewers then receive email notification that contains their login name (as currently filed in $C N G R E Q$ ), the $C R$ id number and description of the change request, and the task leader's initial comments. The technical reviewers examine the request and email their comments to cngbochs@s60.es.llnl.gov, using the procedure exemplified below.

\section{EXAMPLE}

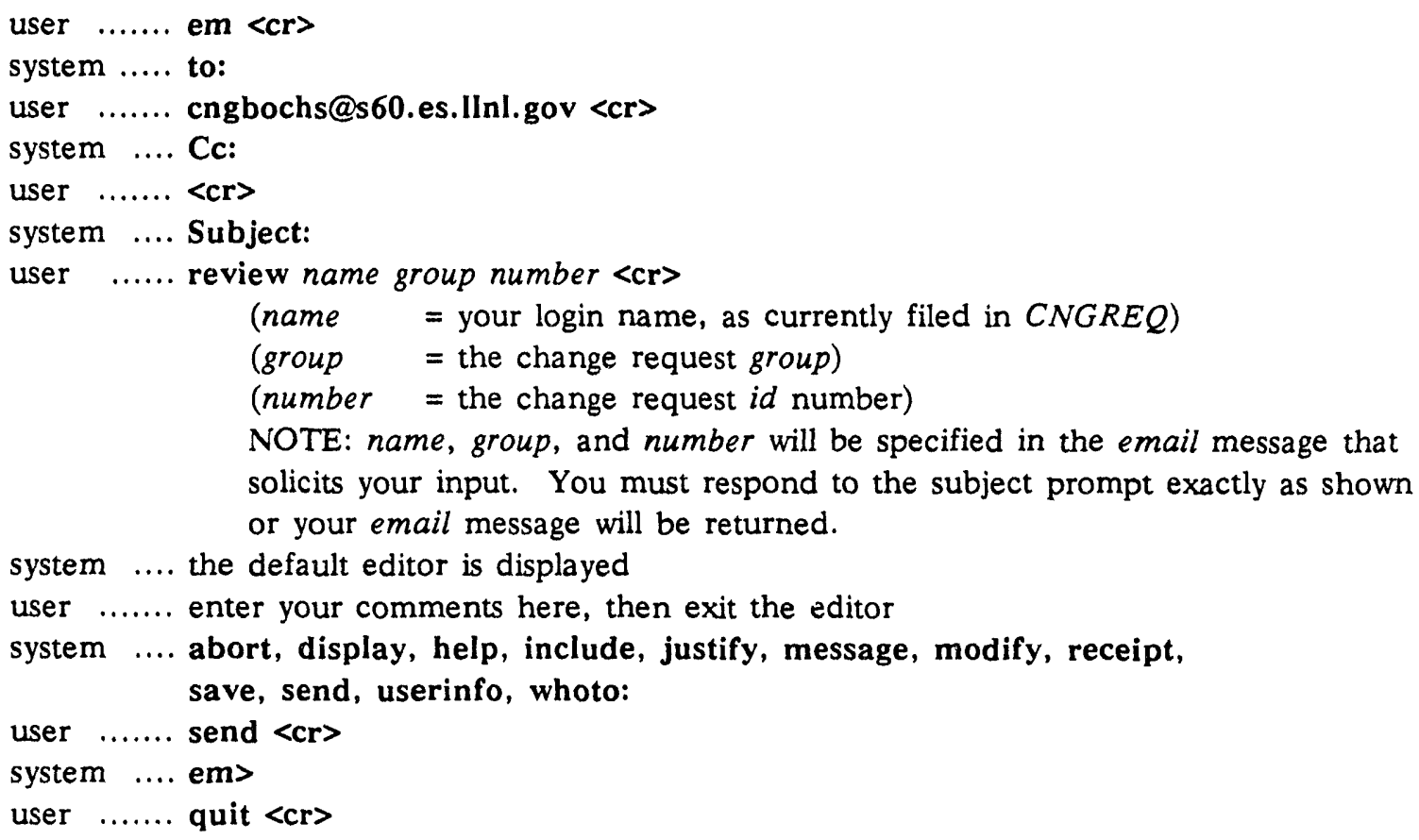

Alternatively, technical reviewers can use $C N G B O C H S$ to enter their comments directly into CNGREQ (see 3.4.2).

When all reviewers have returned their responses, the task leader is notified automatically, then uses CNGBOCHS (see 3.4.1) to review these responses and classify the request as either "invalid", "error", "new data" or "other". If the request is classified as "invalid", its status is set to "completion"; otherwise, the task leader uses CNGBOCHS to enter an appropriate resolution strategy, assign one or more programmers to implement this strategy, and select a verifier to ensure tiat it has been 
implemented correctly. At this point, the request's status is upgraded to "assigned" and the programmers are notified of their assignment via email.

A change request will revert back to "review" from "assigned" status if any of the assigned programmers encounter insurmountable difficulties while attempting to implement the proposed modifications. In such cases, the task leader has two options: (1) provide further instructions that resolve the problem, then reset the classification of the request (to "error", "new data", or "other"), or (2) reclassify the request as "invalid", which automatically sets its status to "completion".

\subsection{2 "Assigned" Status}

During "assigned" status, the assigned programmers attempt to implement the resolution strategy proposed by the task leader. After completing this assignment, they use CNGBOCHS (see 3.4.3) to input the status of their work. If the modifications have been entered successfully, they set the programmers' status field for the request to "finished" and enter whatever comments they might have in the programmers' comments field; the request is then automatically set to "verification" status, and the verifier is so-notified via email. If one or more of the programmers run into difficulties that require clarification, they set the programmers' status field to "problem found" and enter explanatory comments the programmers' comments field; the request automatically reverts to "review" status, and the task leader is so-informed.

A change request reverts back to "assigned" from "verification" status if the assigned verifier discovers a problem with the programmer's implementation. In this case, the programmers have two options: (1) resolve the problem, then reset their status field to "finished", or (2) enter explanatory remarks in their comments field, then solicit advice from the task leader by resetting their status field to "problem found".

\subsection{3 "Verification" Status}

During "verification" status, the verifier reviews the modifications incorporated by the programmers to ensure their correctness. If this review is successful, the verifier uses CNGBOCHS to activate the "finished" column in the verifier's status table field; the status of the change request is then automatically set to "completion". If the verifier feels that something is incorrect, they activate the "problem found" column and explain the problem in the comments field; the status of the change request then automatically reverts to "assigned", and the programmers are so-informed via email. 


\subsection{4 "Completion" Status}

When a change request achieves "completion" status, it has been resolved; the task leader and requester are so-notified via email.

\subsection{The CNGBOCHS-CNGREQ Interface}

CNGBOCHS is a form-based FORTRAN77-EQUEL program that facilitates direct user interaction with the $C N G R E Q$ database. $C N G B O C H S$ permits those having a login account on node s60.es.llnl.gov of the local Sun network and appropriate permissions to view, relationally search, list, and print selected change requests, and to update those fields of the requests for which they have write access. In this section, we describe the access requirements and start-up procedure for using $C N G B O C H S$, provide a complete summary and examples of all run-time options, and detail those option sequences most frequently used by local task leaders, technical reviewers, programmers, and verifiers.

\subsection{CNGBOCHS Access Requirements}

To use CNGBOCHS you must have access to a login account on node s60.es.llnl.gov of the local Sun network, and this account must be designated as a valid Ingres user (for help with these matters, see the GEMBOCHS database administrator). In addition, it is necessary to have several unix environment and shell variables defined appropriately in the .login file of this user account. Specifically:

set path $=($... must include /ingres/ingres/bin and /usr/local/bin $)$ setenv ING_HOME/pubusr/ingres

setenv TERM_INGRES sunkwin setenv II_SYSTEM /ingres setenv MYPATH ... must include /ingres/ingres/bin and /usr/local/bin setenv PATH ... must include /ingres/ingres/bin and /usr/local/bin setenv CNGBOCHS_INTERLEAF_DIR full_path_of_desktop

(e.g., s05:/us/johnson/desktop)

\subsection{CNGBOCHS Start-up Procedure}

Presuming that all of the access requirements described above have been met, CNGBOCHS can be run by logging onto s60.es.llnl.gov from any Shell-Tool (but not Command-Tool!) window and typing "cngbochs" at the system prompt. The blank change-request form that appears on the screen is the user interface to the CNGREQ database; because of size constraints, only a portion of this form can be displayed at 
any one time. The top portion, which appears when one first invokes $C N G B O C H S$, is illustrated in Figure 2; the complete form is given in Appendix A.

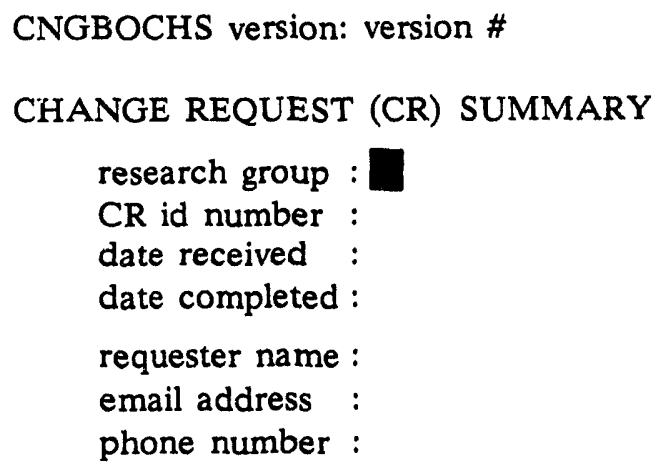

TASK LEADER'S REVIEW

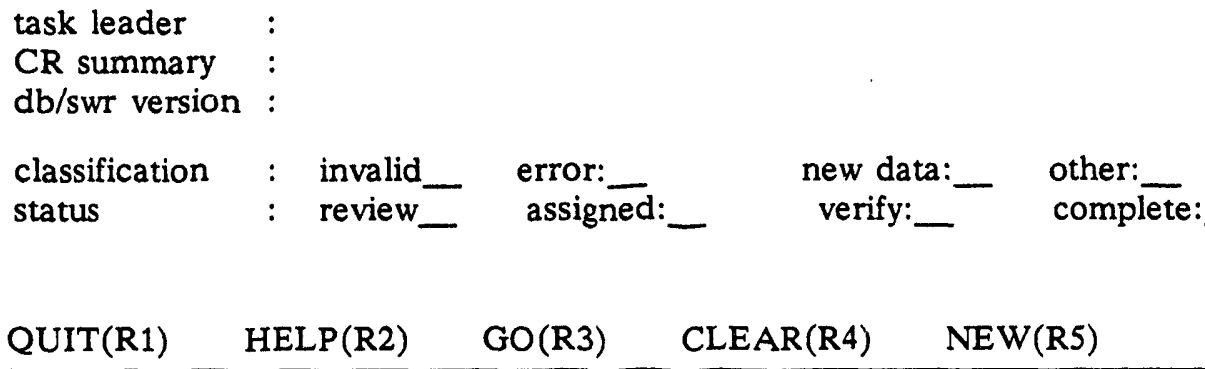

Figure 2

The change-request form consists of "fields", which contain and display only one datum (e.g., the research group field), and "table fields", which contain and display multiple rows and/or columns of data (e.g., the $C R$ description table field). The cursor defines your current location on the form; its initial position is in the research group field. To move the cursor within a given field, use the arrow keys in the usual way (table fields often contain more rows of data than are displayed); to move it between fields, press either the tab key, to move forward, or control-P ( $\left.{ }^{\wedge} \mathbf{P}\right)$, to go backward. The displayed portion of the form will change as required by movement of the cursor.

The fields that you are allowed to edit (enter, delete, or modify data) depend upon who you are (more specifically, what login account you're using!), what you're trying to do, and when you're trying to do it. Change requesters, task leaders, technical 
reviewers, programmers, verifiers, and $C N G B O C H S$ itself all have access to different sets of fields at different times during the evolution of a given change request. Those individuals having general access to specific fields are listed in those fields on the sample change request form given in Appendix A. The basic rule of thumb is that if your responsibilities require you to edit a field, you can; if they don't, you can't. If you try to modify the contents of a field for which you lack permission, CNGBOCHS will respond with the message "not a valid command for browse mode".

Several commonly used editing keys are listed below:

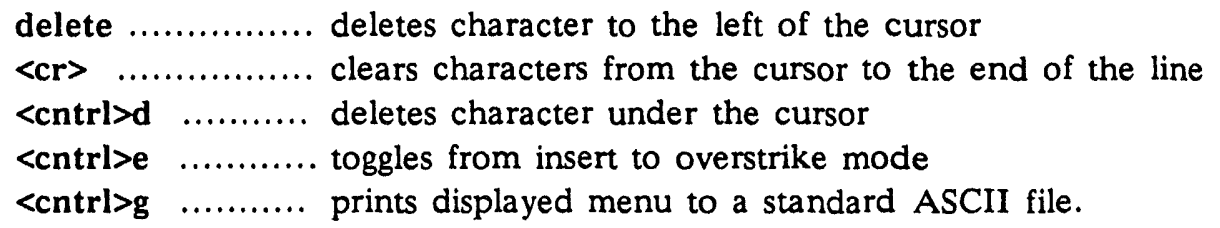

Whenever possible, your input data are checked for validity. CNGBOCHS will recognize most attempts to enter invalid data, inform you as to the nature of acceptable data, then prompt you for such data.

At the very bottom of the screen is a single line that consists of single-word commands separated by blanks; this is the menu of CNGBOCHS run-time options. When the character " $>$ " is shown to the right of the option menu, more options exist than can be displayed at one time. To view these additional options, use the function key R11; press it once to move the cursor to the menu bar, then additional times to scroll through the menu bar line by line. Scrolling in this manner, the last line of options is distinguished by the first appearance of the character " $<$ " at the start of the line; additional scrolling now moves in reverse.

Any of these run-time options may be selected from anywhere on the form by pressing the appropriate function key (except for the HELP and LIST options; see below), which is defined parenthetically to the right of the option name on the menu bar. Alternatively, one can press the R11 key once, then type the option name (or minimum number of unique characters) at the ":" prompt (currently, this must be done for the HELP and LIST options). After a menu-bar option has been selected, a new form and associated menu bar will be displayed; these differ depending upon which option has been selected.

\subsection{CNGBOCHS Run-time Options}

In this section, we describe all of the CNGBOCHS run-time options, and provide examples that illustrate their effective use. 


\subsubsection{QUERY (R4): Interactive Specification of CNGREQ Queries}

When $C N G B O C H S$ is first invoked and the blank change request form illustrated in figure 2 is displayed, the program is in QUERY mode. This mode allows the user to define relational queries that can be subsequently directed to the CNGREQ database (using the GO option, as described in 3.3.2). These queries are specified by scrolling through the form (as described above in 3.2), and entering the values of interest for each relevant data field. For fields that contain numeric or calendar data, search values may be prefixed with one of the following comparison operators: "=" (equal to, which is presumed implicitly with the exception of the value "blank", as described below), "!=" (not equal to), "<=" (less than or equal to), "<" (less than), ">" (greater than), and " $>=$ " (greater than or equal to). These operators can also be used in any logical combination; e.g., the first quarter of FY93 could be represented as ">30-sep-1992 and <1-jan-1993". When specifying values for character data, one may use the usual wildcard characters: "*" (matches any character string) and "?" (matches any single character).

If a data field is left blank (no value specified) when defining a query, then this query will match all values for the field except for the blank entries themselves. These blank entries can be matched by specifying " $=$ " in the field; similarly, all non-blank entries can be matched by specifying " $!="$.

In the following exampie, the user defines a query that will match all GEMBOCHS change requests that were submittea during the last quarter of FY92, and have not yet been resolved.

EXAMPLE.
user ....... cngbochs <cr >
system ..... in query mode
user ....... (in the field research group) gembochs
user ....... tabs cursor to the field date received
user ....... >30-jun-1992 and <1-oct-1992
user ....... tabs cursor to the field date completed
user ....... enters " $="$, which completes definition of the query

NOTE: This query can be directed to CNGREQ by following the example provided in 3.3.2.

\subsubsection{GO (R3): Directing Queries to CNGREQ}

Selection of the GO option initiates a search of CNGREQ for all change requests that match the set of data field values currently displayed; these values were specified by the user while the program was in QUERY mode (see 3.3.1). The matching requests are stored in a match queue, the first entry of which is displayed, and a new menu of run-time options is activated: QUIT, HELP, GO, QUERY, SAVE, WRITE, and LIST. 
QUERY returns the program to QUERY mode (see 3.3.1), each subsequent selection of GO displays the next request in the match queue, and the other options are described later in 3.3.

If no change requests in $C N G R E Q$ match the specified query, the message "no change requests selected [hit return]" is displayed; following the indicated carriage return, the program returns to QUERY mode. Otherwise, one can scroll through the queue of matching requests, displaying each in sequence with additional GOs. When GO is selected while the last request is displayed, the program prints "end of selected change requests [hit return]"; again, CNGBOCHS returns to QUERY mode following the carriage return.

While viewing a given request in the queue, users can tab through the form and enter or modify values within any data field for which they have write access. Within table fields, one can search for character strings by pressing <cntrl>-F (on some machines the alt key also works) and entering the search string after the prompt "Enter string to find: ". If a match is found, the cursor is moved to the matching row, and the displayed portion of the table field scrolled if necessary. If no match is found, the program responds with "Could not find value [hit return]".

EXAMPLE.

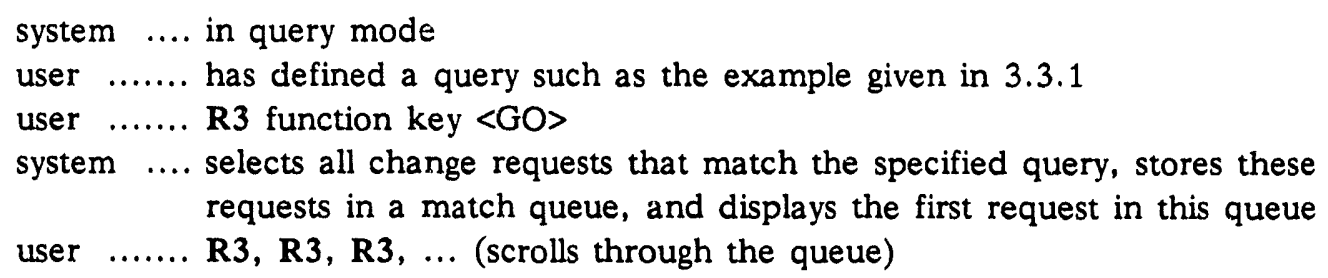

NOTE: One can list the contents of this queue to an ASCII file using the LIST option (see 3.3.3), save updates to one or more of the matching requests using the SAVE option (3.3.4), and print selected requests using the WRITE option (3.3.5).

\subsubsection{LIST: Writing Selected Change Requests to an ASCII File}

When the LIST option is selected, the research group, CR id number, and CR summary fields of all change requests in the queue are written to an ASCII file whose name is specified by the user. (Note that there is no function key associated with this option.)

\section{EXAMPLE}

user ....... has used the GO option to generate a non-empty match queue, as exemplified in 3.3.2

system ..... displaying a change request from the match queue

user ...... R11 function key; enter list <cr> <LIST>

system ..... File name to write:

user ....... queue_list 
system .... writes the research group, $C R$ id number, and $C R$ summary fields of all change requests in the match queue to the ASCII file queue_list

\subsubsection{SAVE (R5): Saving Modified or New Requests to CNGREQ}

When the SAVE option is selected, CNGBOCHS writes the change request currently displayed to the $C N G R E Q$ database. This request may already exist in $C N G R E Q$ (but has been modified during the current $C N G B O C H S$ session) or it may be a new request. If it exists in CNGREQ, then the updated version will overwrite the older one; if the modifications cause the request to change status, all relevant parties will be informed automatically via email. (If one attempts to save an existing request that has not been modified, the system will respond with "No changes were made [hit return]".)

EXAMPLE (saving a modified request)

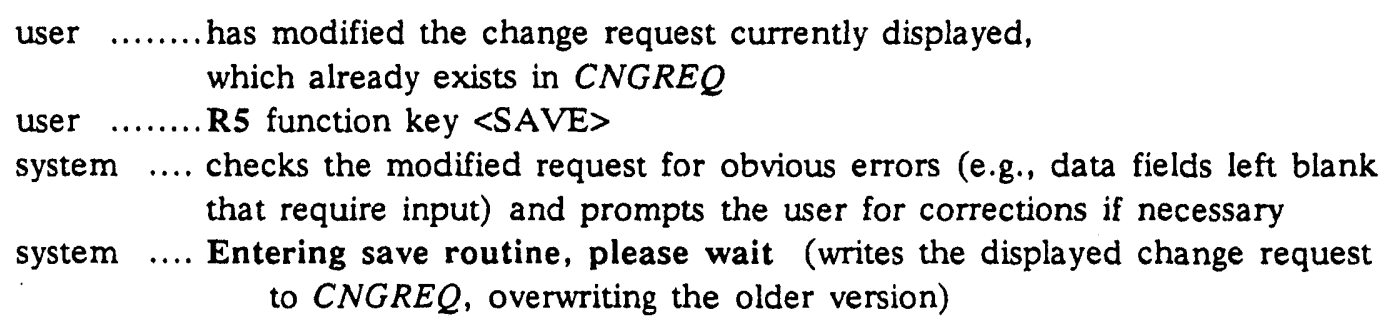

If the change request to be saved is new (see 3.3.6), the procedure is only slightly different than that described above.

EXAMPLE (saving a new request)

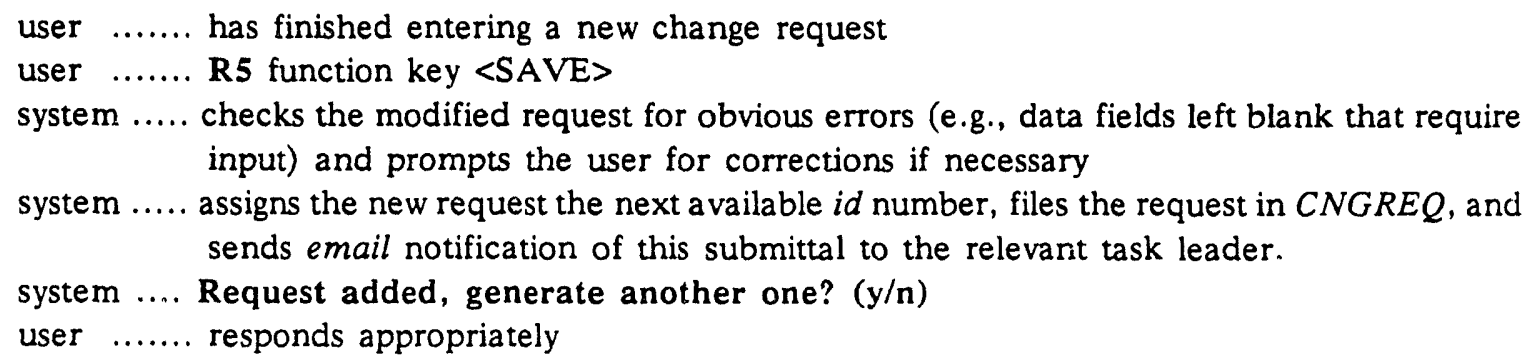
input) and prompts the user for corrections if necessary

system ..... assigns the new request the next a vailable id number, files the request in $C N G R E Q$, and sends email notification of this submittal to the relevant task leader.

system .... Request added, generate another one? $(y / n)$

user ....... responds appropriately

\subsubsection{WRITE (R6): Printing Selected Change Requests}

When the WRITE option is selected, the request currently displayed is written to an Interleaf-formatted file which will be placed in the present working directory. This file will also be copied to your personal Interleaf desktop directory if the unix environment variable CNGBOCHS_INTERLEAF_DIR is appropriately defined in your .login file; the new file will overwrite a previously existing file of the same name. 
EXAMPLE - (where CNGBOCHS_INTERLEAF_DIR is set to s05:/us/johnson/desktop)

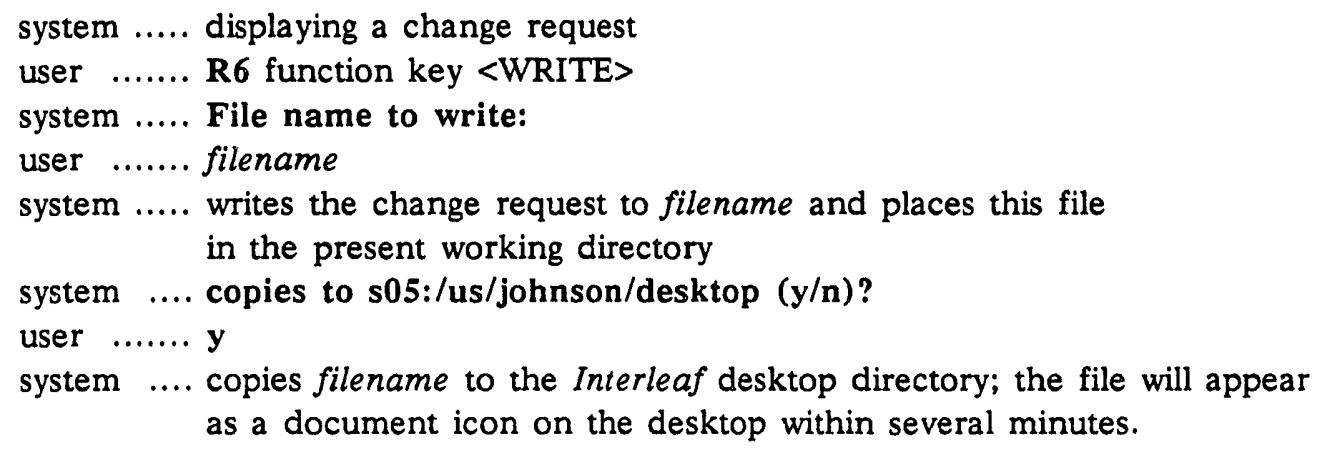

\subsubsection{NEW (R5): Entering a New Change Request}

This option allows the user to create a new change request and file it in the CNGREQ database. (Alternatively, new requests can be submitted using the standard email system, as described in 2.1). If this option is selected, a new change request form is displayed, the values of all data fields known to the system are entered automatically (e.g., requester name, email address, and phone number), and a new menu of run-time options appears: QUIT, SAVE, and QUERY. The user then defines the new request by moving through this form and entering values for the appropriate fields (in general, these are the research group, $C R$ description, and $d b / s w r$ version fields).

\section{EXAMPLE}

system .... in query mode

user ..... R5 function key <NEW>

system ... A new change request form is displayed, the menu of run-time options is updated, and current values for the requester name, email address, and phone number are entered automatically if the the login account you are using is known to CNGBOCHS. You now have edit access to these three fields as well as to research group, $C R$ description, and db/swr version.

user ..... Modifys or fills in values for the fields requester name, email address, and phone number. Enters values for the field research group, table field $C R$ description (a complete description of the change request), and field $d b / s w r$ version, if appropriate.

NOTE: This new request can be filed in CNGREQ using the SAVE option (3.3.4).

\subsubsection{CLEAR (R4): Clearing the Displayed Change Request Form}

When the CLEAR option is selected, all field values currently specified on the displayed change request form are cleared; the cursor remains in the position it occupied when CLEAR was selected. 


\title{
EXAMPLE
}

\author{
system ... in query mode \\ user .... moves through the form and enters values for several data fields; \\ tabs to the table field $C R$ description. \\ user ..... R4 function key <CLEAR> \\ system .... all previously specified data-field values are cleared; \\ the cursor remains in the table field $C R$ description
}

\subsubsection{HELP (R2): Getting On-line Help}

When the HELP option is selected, the menu of query-mode run-time options is replaced with the Ingres help menu, and the cursor is placed at the end of this line. The Ingres help options WhatToDo, Keys, Field, Help, and End, are summarized below; the function keys that activate these options are given parenthetically. (Currently, HELP (or Keys; see below) cannot be accessed using the indicated function key (R2); to select these options, move the cursor to the menu bar (R11), then enter the appropriate character string: " $h<c r>$ " or " $k<c r>$ ".)

\footnotetext{
WhatToDo (R1) ... displays a summary of each option available on the CNGBOCHS query-mode menu

Keys (R2) ........... displays a table of the mapping between the function and control keys, and their current definition for the CNGBOCHS query-mode menu

Field (R3) .......... displays information about what values are allowed in the field where the cursor is currently positioned

Help (F2) .......... displays the information provided in this list

End (F3) ............ returns you to the CNGBOCHS query-mode menu
}

\section{EXAMPLE}

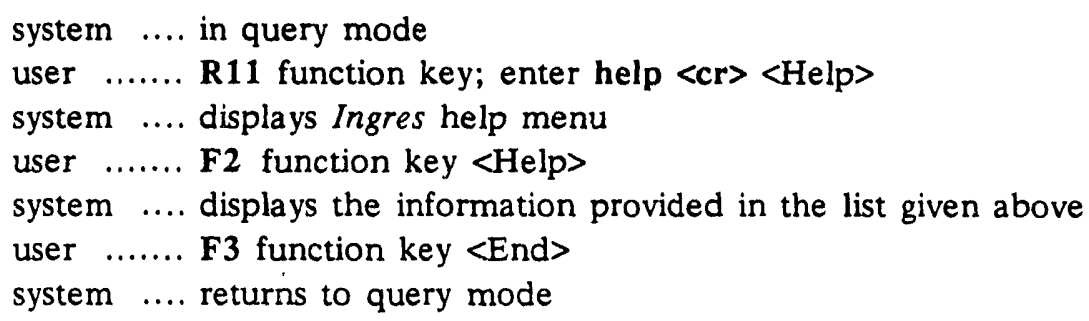

\subsubsection{QUIT (R1): Exiting CNGBOCHS}

Selecting the QUIT option allows you to exit $C N G B O C H S$ at any time. If the change request currently displayed has been modified, you must confirm the exit, as illustrated in the following example. 


\section{EXAMPLE}

system .... displaying a change request; a field has been changed

user ....... R1 function key <quit>

system .... Quit without saving changes ? (y/n)

user ....... y

system .... CNGBOCHS exits; the change request is unchanged

\subsection{Use of CNGBOCHS by Local Research Groups}

Specific combinations of the run-time options described above are frequently used by task leaders, technical reviewers, programmers, and verifiers associated with local research groups, e.g. GEMBOCHS and $E Q 3 / 6$. In this section, we provide generic examples of these combinations that track the evolution of mythical change request GEMBOCHS 123.

\subsubsection{Task Leaders}

The GEMBOCHS task leader has received email notification that a new change request has been received; it has been set to "review" status and assigned the $C R$ id number 123. After reviewing this request, the task leader uses $C N G B O C H S$ to enter some initial comments and solicit an additional technical review. If the requester's login name is unknown to $C N G R E Q$, the task leader must also transfer the requester's full name and phone number from the request into the appropriate $C N G R E Q$ fields.

\section{EXAMPLE}

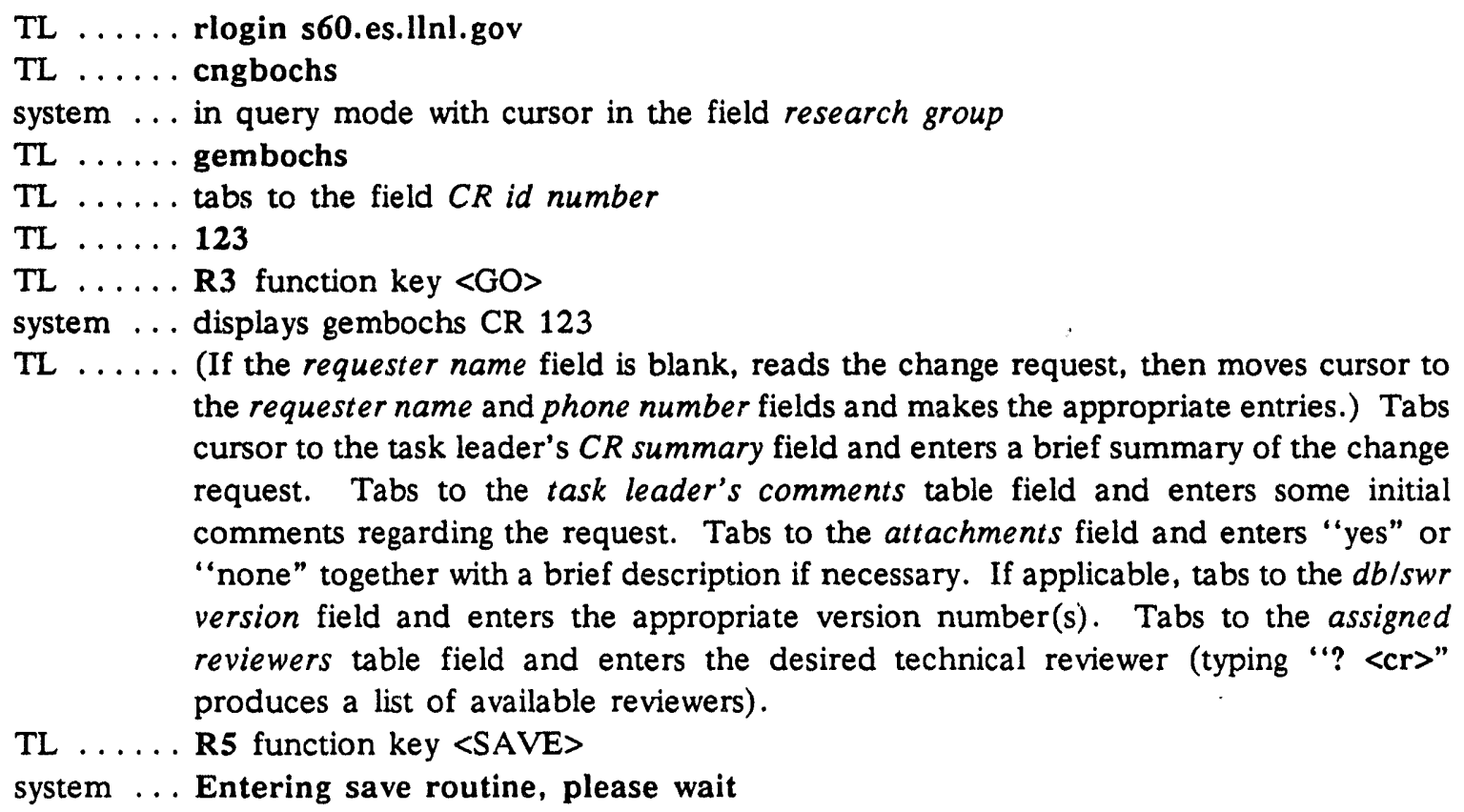
the requester name and phone number fields and makes the appropriate entries.) Tabs cursor to the task leader's $C R$ summary field and enters a brief summary of the change request. Tabs to the task leader's comments table field and enters some initial comments regarding the request. Tabs to the attachments field and enters "yes" or "none" together with a brief description if necessary. If applicable, tabs to the $d b / s w r$ version field and enters the appropriate version number(s). Tabs to the assigned reviewers table field and enters the desired technical reviewer (typing "? <cr>" produces a list of available reviewers).

TL . . . R5 function key $\langle$ SAVE $>$

system ... Entering save routine, please wait 
system ... Sends an email note to the selected reviewer(s); this note includes a description of the change request, the task leader's initial comments, and instructions on how to return the review comments via email.

Several days later, $C N G B O C H S$ has informed the task leader that the solicited technical review has been returned via email (see 2.2.1 for procedural details) and filed in the CNGREQ database. This email note includes the original description of the change request, the task leader's initial comments, and the technical reviewer's remarks. The task leader now uses $C N G B O C H S$ to classify the request, describe an appropriate resolution strategy, assign programmers to implement this plan, and assign a verifier to ensure its accurate implementation.

EXAMPLE

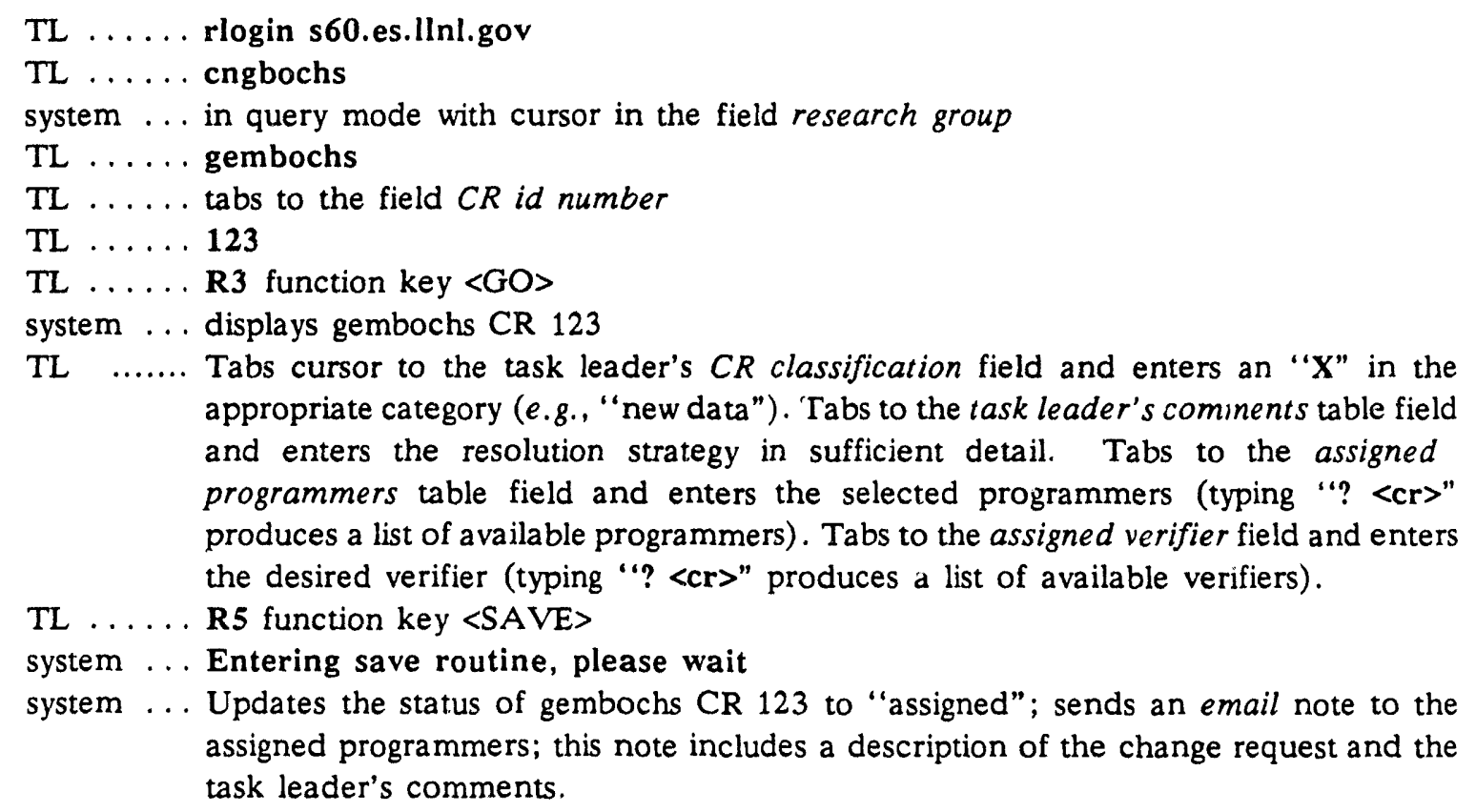

\subsubsection{Technical Reviewers}

The assigned technical reviewer for GEMBOCHS CR 123 has received email notification of this assignment, and prefers to submit the review via $C N G B O C H S$, instead of responding through email (see 2.1).

\section{EXAMPLE}

reviewer . rlogin s60.es.llnl.gov

reviewer . . cngbochs

system .... in query mode with cursor in the field research group

reviewer .. gembochs

reviewer .. tabs to the field $C R$ id number 


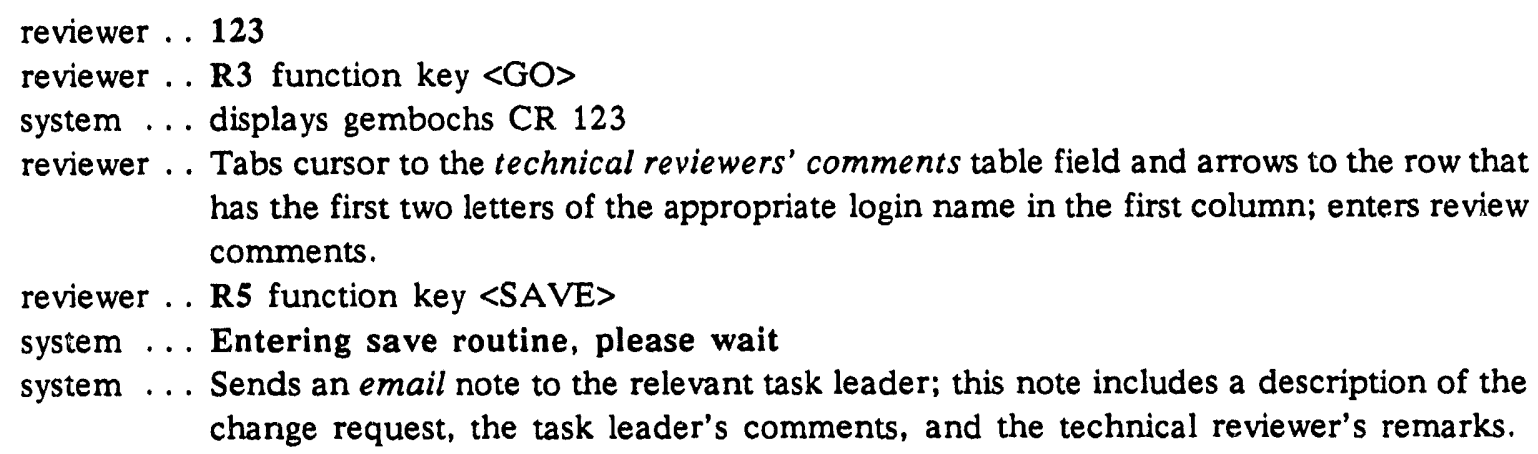

\subsubsection{Programmers}

Each assigned programmer has received email notification that the status of GEMBOCHS CR 123 has been upgraded to "assigned"; i.e., it has been reviewed and a resolution strategy proposed, which the programmers are responsible for implementing. After completing their work, each programmer uses $C N G B O C H S$ to report the status of the assignment and any relevant comments.

\section{EXAMPLE}

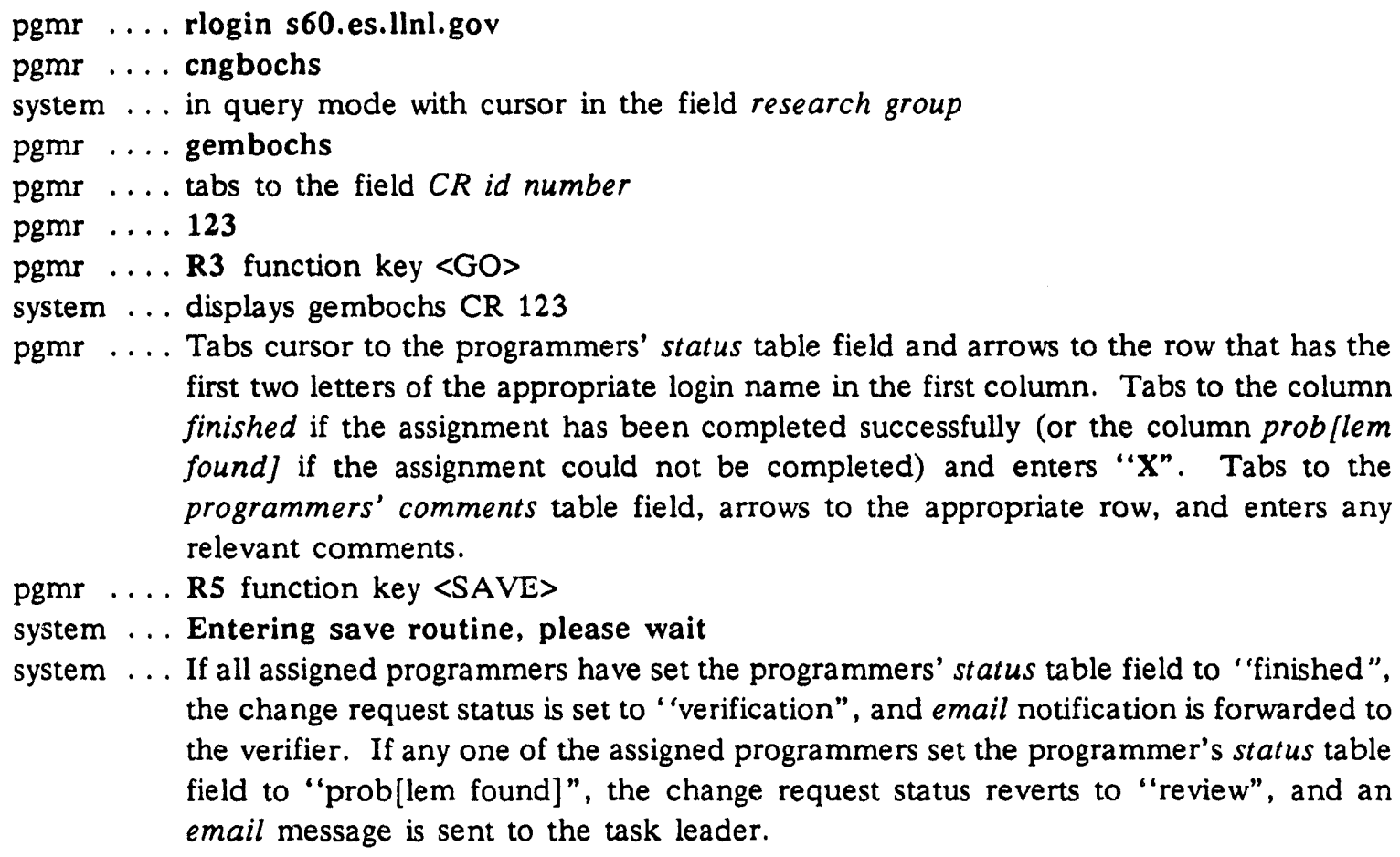

\subsubsection{Verifiers}

The assigned verifier has received email notification that the status of GEMBOCHS CR 123 has been upgraded to "verification"; i.e., it has been reviewed by the task leader and the resulting resolution strategy successfully implemented by the assigned 
programmers. After reviewing the modifications incorporated by the programmers, the verifier uses $C N G B O C H S$ to report the status of the review and any relevant comments.

\section{EXAMPLE}

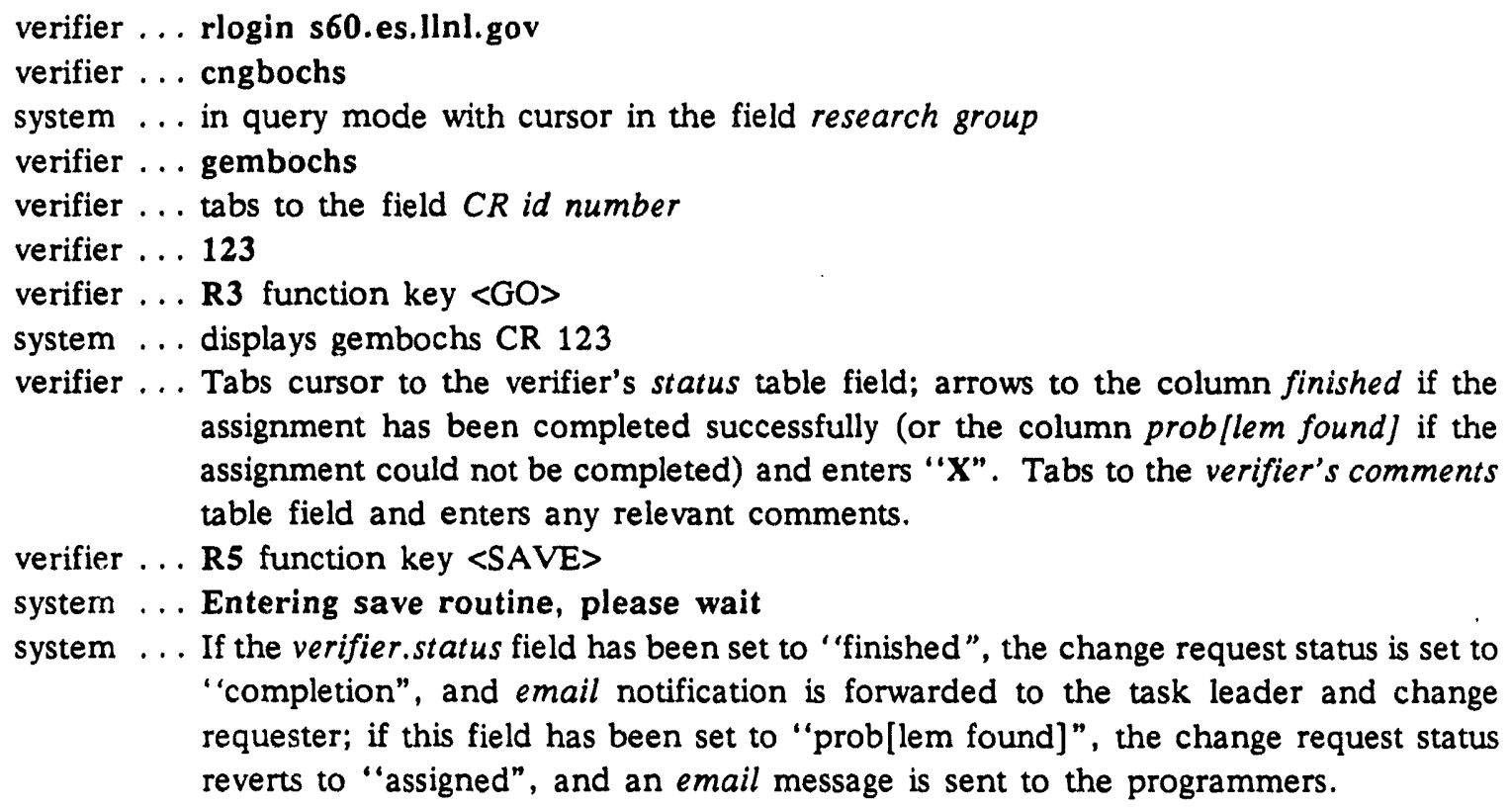
assignment has been completed successfully (or the column prob [lem found] if the assignment could not be completed) and enters " $X$ ". Tabs to the verifier's comments table field and enters any relevant comments.

verifier ... R5 function key <SAVE $>$

system ... Entering save routine, please wait

system ... If the verifier.status field has been set to "finished", the change request status is set to "completion", and email notification is forwarded to the task leader and change requester; if this field has been set to "prob[lem found]", the change request status reverts to "assigned", and an email message is sent to the programmers.

\subsection{Concluding Remarks}

The $C N G B O C H S$ software package provides a easy-to-use, secure system for documenting the evolution of change requests submitted to GEMBOCHS, EQ3/6, or other research groups from their initial submittal to their final resolution. The package is based on the widespread availability and use of the standard electronic mail system (email), which has been successfully interfaced with a dedicated Ingres relational database and the Interleaf desktop publishing package. This integrated Ingres-Email-Interleaf system permits research groups and their associates to use email for all correspondence associated with the submittal and resolution of change requests, and maintains the complete history of each such request in a relational database (CNGREQ) that can be queried and updated using a form-driven interface $(C N G B O C H S)$ and selectively printed using a built-in interface to Interleaf. 


\section{Appendix A: CNGBOCHS Change-Request Form}

CNGBOCHS version: version \#

CHANGE REQUEST (CR) SUMMARY

research group : program, requester

$\mathrm{CR}$ id number : program

date received : program

date completed : program

requester name : program, requester, task leader

email address : program, requester, task leader

phone number : program, requester, task leader

\begin{tabular}{|l|}
\hline CR description \\
\hline \\
\hline \\
\hline \\
\hline \\
\hline \\
attachitially filled by program or requester \\
\hline \\
\hline
\end{tabular}

TASK LEADER'S REVIEW

task leader : program

CR summary : TASK LEADER

$\mathrm{db} / \mathrm{swr}$ version : TASK LEADER

CR classif'n : invalid:

CR status : review:

error : new data: assigned:_ verify :-

other :

$<-$ TASK LEADER

completion:

<- PROGRAM

task leader's comments

TASK LEADER

\begin{tabular}{|l|l|}
\hline CR species & formulas \\
\hline TASK LEADER & TASK LEADER \\
\hline & \\
\hline
\end{tabular}

assigned reviewers

TASK LEADER assigned programmers

TASK LEADER assigned verifier:

TASK LEADER

\section{QUIT(R1) HELP(R2) GO(R3) CLEAR(R4) NEW(R5)}

QUIT(R1) HELP(R2) GO(R3) QUERY(R4) SAVE(R5) WRITE(R6) LIST 


\section{Appendix A: CNGBOCHS Change-Request Form (Continued)}

TECHNICAL REVIEWS

\begin{tabular}{|l|l|l|}
\hline name & date notified & date returned \\
\hline program & program & program \\
\hline & & \\
\hline
\end{tabular}

\begin{tabular}{|l|l|}
\hline id & technical reviewers' comments \\
\hline program & TASK LEADER, REVIEWER (using login name), or program \\
\hline & \\
\hline & \\
\hline
\end{tabular}

PROGRAMMERS' STATUS

\begin{tabular}{|l|l|l|l|l|}
\hline name & date notified & received & finished & prob \\
\hline program & program & programmer & programmer & pgmmer \\
\hline & & & & \\
\hline
\end{tabular}

\begin{tabular}{|l|l|}
\hline id & programmers' comments \\
\hline program & TASK LEADER, or PROGRAMMER (using login name) \\
\hline & \\
\hline & \\
\hline
\end{tabular}

VERIFIER

\begin{tabular}{|lllll|}
\hline $\begin{array}{l}\text { name } \\
\text { program }\end{array}$ & $\begin{array}{l}\text { date notified } \\
\text { program }\end{array}$ & received & finished & prob \\
& verifier & verifier & verifier \\
\hline
\end{tabular}

\begin{tabular}{|l|l|}
\hline id & verifier's comments \\
\hline program & TASK LEADER or VERJFIER (using login name) \\
\hline & \\
\hline & \\
\hline
\end{tabular}

$\begin{array}{lllllll}\text { QUIT(R1) } & \text { HELP(R2) } & \text { GO(R3) } & \text { CLEAR(R4) } & \text { NEW(R5) } & & \\ \text { QUIT(R1) } & \text { HELP(R2) } & \text { GO(R3) } & \text { QUERY(R4) } & \text { SAVE(R5) } & \text { WRITE(R6) } & \text { LIST }\end{array}$




\section{Appendix B: CNGBOCHS Interleaf Document}

CNGBOCHS Version: 3.0

CHANGE REQUEST (CR) SUMMARY

Research Group :

CR id number :

Date Received :

Date Completed :

Requester Name:

Email Address :

Phone Number :

CR description:

Attachments :

\section{TASK LEADER'S REVIEW}

Task Leader :

CR Summary :

$\mathrm{Db} \mid$ Swr Version :

CR Classif'n :

CR Status

Task Leader's Comments:

CR Species

Formulas

Assigned Reviewers

Assigned Programmers

Assigned Verifier 


\section{Appendix B: CNGBOCHS Interleaf Document (continued)}

TECHNICAI REVIEWS

Name

Comments

PROGRAMMERS' STATUS

Name

Comments

VERIFIER'S STATUS

Name

Comments
Date Notified

Date Returned
Date Notified

Status 

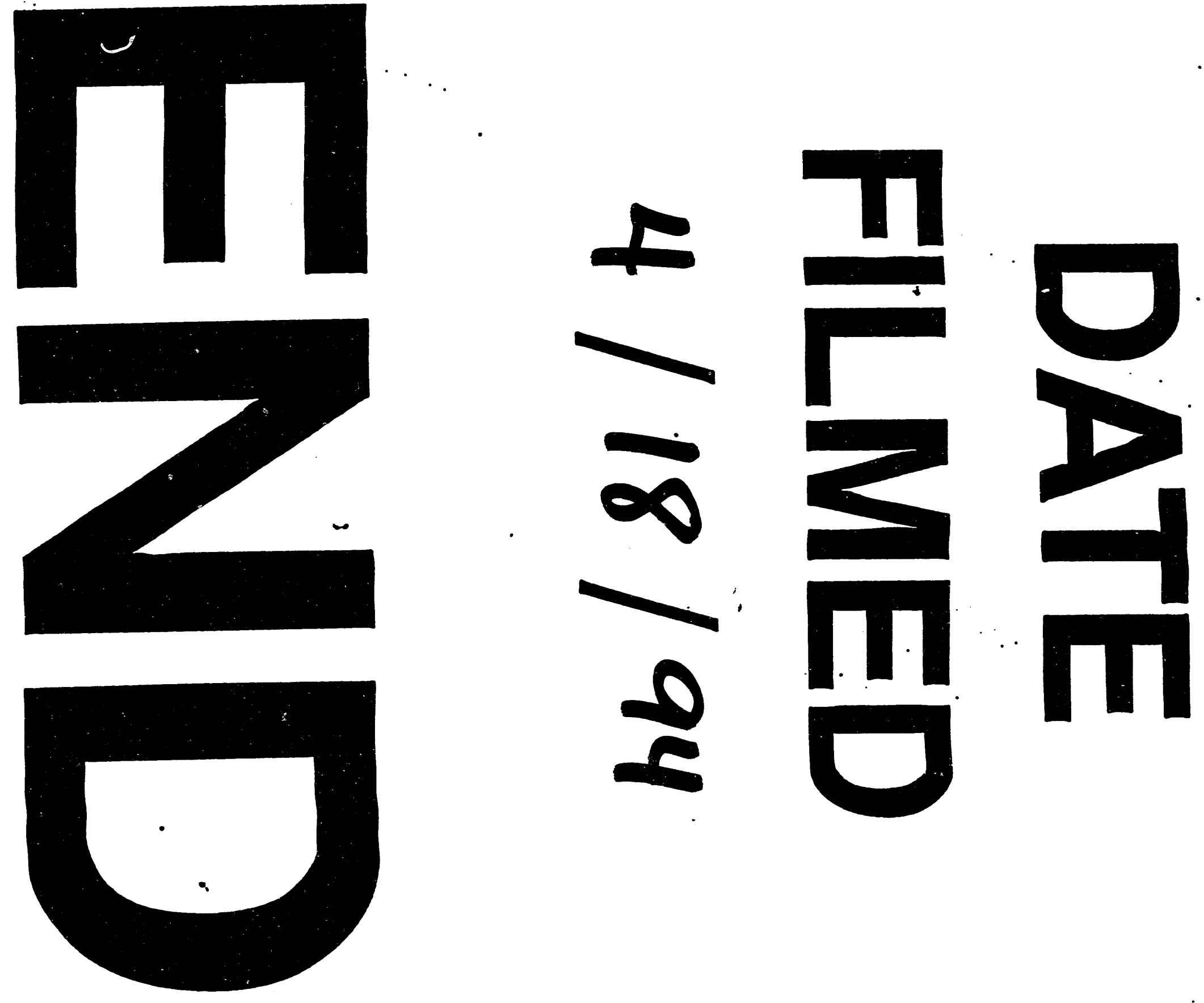

$\pm 0$

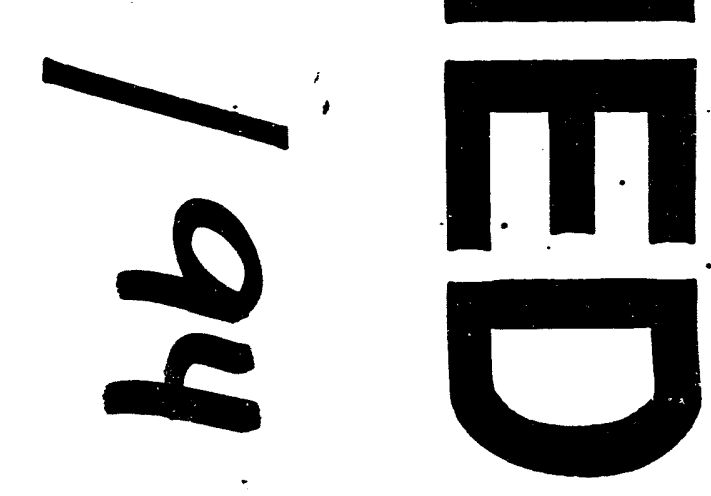

